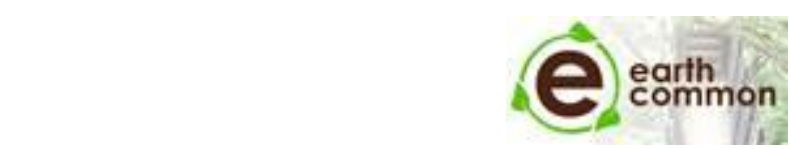

Earth Common Journal Special Issue

$e^{3}=$ earth education economics

1st PRME Canada Regional Meeting held on June 12, 2013

MacEwan University, School of Business

Volume 3, Number 2, September 2013

\title{
Barriers for women to positions of power: How societal and corporate structures, perceptions of leadership and discrimination restrict women's advancement to authority
}

Dee-Ann Schwanke*

MacEwan University, Canada

\begin{abstract}
Women's advancement in the corporate workplace has taken significant strides over the last century. Research demonstrates, however, that despite an increased presence of female employees in mid-management positions, executive positions continue to be male dominated. Women are underrepresented in areas of governance, directorship, and executive leadership. This seems to contradict the apparent momentum of the promotion of women. This paper will unveil some of the hidden barriers that stubbornly exist for women in business. It will review research that demonstrates why gender inequality is difficult to recognize, the systems that perpetuate it, the complexities of how society views it, and the ways women respond to it. By understanding the interplay between external and internal obstacles, women who wish to assume positions of leadership can more easily navigate the labyrinth of gender inequality, and their male colleagues can
\end{abstract}


better recognize the ways that they can either remove barriers or encourage equality. There are corporate, social and economic benefits to allowing women to fairly advance to positions of power. Recognizing and removing barriers is vital to the strength of companies, social networks and jurisdictions.

\section{Introduction}

Women's advancement in the workplace has taken significant strides in the past 50 years. Research demonstrates, however, that despite an increased presence of female employees in mid-management positions, executive positions across the globe continue to be dominated by men. By presenting the current presence of females in management positions with comparisons to housewives of the 1960s, media and cultural references assume and celebrate that women have achieved equity (Schmitt, Spoor, Danaher, \& Branscombe, 2009, p. 49) when they have not. This contradiction between perceived equality and ongoing statistical inequality creates confusion; despite optimistic views that women have broken through barriers to senior positions, they are, in fact, still underrepresented in governance, directorship, and executive leadership. Why does this misrepresentation still exist, and what barriers do women still face in becoming top leaders of organizations?

\section{The Labyrinth: Women's Barriers to Positions of Power}

According to Cornell University, the "glass ceiling" is a metaphor first used by Nora Frenkiel in Adweek in March 1984 (Catherwood Library, 2005) to explain the subtle, invisible obstacles women face after they attain mid-management positions. They advance to the top of middle management but are unable to pass through this barrier. Media and contemporary messaging communicate that this glass ceiling is being shattered; the stark reality is that it still exists (Schmitt, Spoor, Danaher, \& Branscombe, 2009 , p. 56). Further, nuances of this restriction are surfacing in new forms, eliciting such terms as glass escalators (Eagly \& Sczesny, 2009, p. 30), slippers (Rudman \& Heppen, 2003, p. 1357), and cliffs (Ryan \& Haslam, 2005, p. 81).

Another term more recently suggested for these barriers is the labyrinth, indicating the complicated, exhausting challenges that women must navigate on their way to senior roles (Guerrero, 2011, p. 382). Although gains have been made in many employment areas, women remain significantly underrepresented in positions of power. Less than $16 \%$ of corporate officers and board members of Fortune 500 companies are women

ECJ Volume 3, No. 2, 2013: $\mathrm{e}^{3}=$ earth education economics 
(Catalyst, 2007, p. 1). These positions have often come at a cost to women who do achieve them. These women carry such burdens as stereotyping, prejudice, sexual harassment, tokenism, and isolation (Barreto, Ryan, \& Schmitt, 2009, p. 9).

The glass ceiling is an easily applied metaphor for women's experiences. In real terms, however, the underlying causes of gender inequality in senior positions are less identifiable or well defined. This paper examines the barriers to women's advancement to senior positions and arranges them into four categories to clarify the complexities of why women hold few powerful roles in industry. They include structural issues in society and in corporate settings. They are demonstrated by prevailing perceptions of gender and leadership. They are presented in forms of prejudices and discrimination. Women's responses to these barriers also complicate the issue.

\section{Structural Issues in Society and Corporate Settings}

Women face two types of structural issues; some are found in society generally, and others are found in corporate settings. Societal issues are those forces which are deeply rooted in culture and public policy. Contributing factors to the limited career advancement for women include some aspects of social programs and policy, limited human capital and the societal expectation of female participation in service industries such as education, health services, and social and community services (Eagly \& Sczesny, 2009, p. 34).

Social policy directed towards women perpetuates inequality in domestic obligations (Eagly \& Sczesny, 2009, p. 39). When maternity leaves are favoured over paternity leaves, or when women are encouraged to work part-time after the birth of a child while men are not given equal opportunity to do so, the social perception that it is more appropriate for women to fulfill the commitment to family responsibilities than for men to do so is reinforced. Although women have increased their participation in the workplace over the last number of decades, their domestic responsibilities have decreased only marginally. Research by Fuwa and Cohen indicates that the average American woman works 13.2 hours per week on housework, compared to her spouse who works approximately 6.6 hours (qtd. in Lachance-Grzela \& Bouchard, 2010, p. 768). This disparity creates an undesirable scenario for women, who are forced to choose an unhealthy work-life balance in order to pursue their careers (Eagly \& Sczesny, 2009, p. 39).

Another societal issue for women is their limited human capital. Human capital refers to the skills, experience, and knowledge an employee brings to a position 
(Canadian Oxford Dictionary, 2005). Cultural expectations deem it more appropriate for women to interrupt their careers due to family responsibilities such as caring for children or aging parents than for men to do the same. In addition, women are encouraged to work in departments that have fewer developmental opportunities or do not translate to executive advancement (Guerrero, 2011, p. 382). Broughton and Miller noted that women in management are more likely to come from non-business backgrounds, which limits their attempts to succeed because they have little or no business leadership experience (Broughton \& Miller, 2009, p. 14). Women may compensate for this lack of experience, however, by developing specialist expertise through higher education degrees (2009, p. 14). Further, the notion of the "glass border" suggests that women do not advance due to their limited international business experience which is often the result of companies typically offering opportunities to travel to male employees first (Broughton \& Miller, 2009, p. 11). Finally, women's wider acceptance in leadership in soft sectors of corporate governance perpetuates stereotypes about gender-based employment (Eagly \& Sczesny, 2009, p. 34).

Although less widespread than societal issues, issues related to corporate structures significantly affect women's potential in a more direct way. Organizational structures can interfere with and inhibit female advancement. These structures include male dominated "old boys networks," increased ambiguity about advancement, and glass cliffs. Existing networks in organizations can often be homogenous and long-standing. They are difficult for women to break into as women are often uncomfortable with networking in the social context of these settings and are also unable to commit the extra time outside of work hours due to their home commitments (Broughton \& Miller, 2009, p. 17). The men also generally have little interest in welcoming new female members. Because of these factors, the support network around women at higher levels of leadership is limited and unhelpful (2009, p. 17).

This corporate culture, together with elements of restrictive social policy, is clearly evident in some gender equality issues surrounding our national police force. The RCMP has spoken openly about the inability of the Canadian RCMP Act to deal with sexual harassment in the force. Cpl. Catherine Galliford, a 20-year veteran of the force, had complained about long term abuse within the RCMP. She claimed that some supervisors treated her as a potential sexual plaything and that she was repeatedly propositioned for sex (The Canadian Press, 2012). RCMP Commissioner Bob Paulson indicated that the structure of the system makes it nearly impossible to address Cpl. Galliford's allegations appropriately, stating that he was working with a system that "was current 25 years ago" (The Canadian Press, 2012). Dysfunctional colleague partnerships that favour one 
gender, such as this example, create an unbalanced perspective that becomes the norm over time.

Another corporate issue is that promotion to senior positions requires more than superior skills and experience. It may be influenced by unclear guidelines and parameters such as amicable relationships with powerful people or other unstated expectations. Further, the ways to participate in opportunities for career development in organizations, such as training or travel, are often veiled in secrecy. This ambiguity increases when the employee is female (Hamel, 2009, p. 239). When trying to navigate through the hidden expectations for job promotion, women's limited natural relationships with men at the top inhibit their abilities to secure senior placements.

The phenomenon of "glass cliffs" is another threat to women entering positions of power. Women are favoured for positions that lead units in crisis, creating a scenario in which burnout or failure is a potential risk (Ryan \& Haslam, 2005, p. 157). Women who push through the glass ceiling are seen as desirable candidates to take over in crisis situations. Due to the limited support network around them, women often find these roles highly stressful, so they often leave their positions. This departure is often attributed to the woman's lack of skills or her unwillingness to commit to the hard work needed at higher levels of leadership. Contrary to this claim that women who leave jobs are not committed to hard work, research has demonstrated that $90 \%$ of women who leave their employment find work elsewhere, $70 \%$ of which is full-time (Townsend, 1996 , p. 35). Despite these encouraging statistics, a consequence of a woman's choice to leave is frequently a lateral move to a company where she must establish herself again.

\section{Prevailing Perceptions of Gender and Leadership}

Although research does not support the suggestion that leadership effectiveness is different between the two sexes, this misperception remains (Guerrero, 2011, p. 382; Rosener, 2008, p. 411). Gender biases that consider leadership qualities to be most closely related to male qualities obstinately persist in some organizational cultures and are difficult to overcome. Women who are perceived to exhibit attributes that are more associated with men are resisted (Guerrero, 2011, p. 383). A society's shared knowledge about what attributes men and women exhibit can be divided into two categories. Descriptive beliefs are how society thinks a man or a woman typically acts (such as gruff or chatty.) Prescriptive beliefs are how society thinks a man or a woman should act (such as courageous or gentle.) In addition to prescribed beliefs about gender, society also holds attitudes towards leadership traits (p. 383). 
Research consistently demonstrates that current society sees leadership traits as closely resembling those which are usually attributed to men (Eagly \& Sczesny, 2009, p. 25; Stelter, 2002, p. 90). The most common descriptors of the different expectations of men and women are "communal" versus "agentic." Communal qualities are most often associated with women and include affection, helpfulness and gentleness. Agentic traits are most often associated with men and include assertion and control. These generalized expectations create a framework for widespread stereotyping in culture and in the workplace (Eagly \& Sczesny, 2009, p. 24). Professional women are also expected, due to societal norms, to replace warmth for competence based on the perception that women cannot be competent and warm at the same time (Cikara \& Fiske, 2009, p. 79-80).

Leadership traits that mirror the agentic style have long been supported as desirable and have been called the "think manager-think male effect" (Eagly \& Sczesny, 2009, p. 26). When women enter positions of leadership, they experience a deep-rooted complexity of expectations where they are preferred to exhibit communal traits as a member of the female gender but at the same time to exhibit agentic traits as a member of leadership. This is a difficult balancing act where women are criticized both for being too masculine and being too feminine (p. 27). This creates stress and frustration for executive women who, despite their efforts, often experience attitudinal penalties by associates and subordinates for not conforming to the perceived role. These penalties may include poor evaluations, criticism, and social rejection (p. 27). In addition, most leadership positions are described using agentic terms, so men are deemed more appropriate for those roles, whether the position is in a field that is seen as traditionally male- or female-oriented (i.e. healthcare or education). Men will therefore accelerate their climb up the corporate ladder, leaving women to slowly ride the glass escalator and to work through external perceptions (p. 30).

Small, slow changes are happening in views about effective leadership. These are starting to lean towards the concept of transformational leadership and away from the agentic, transactional standard (Eagly \& Sczesny, 2009, p. 36). Women have proven themselves in soft sectors as executive leaders (p. 34), including human resources and healthcare. Unfortunately, the absence of female leaders in other industries still demonstrates significant inequity. Limited change in social roles has resulted in little change in stereotyping, but the adoption of a larger understanding of leadership may eventually prove helpful for women to be more accepted in senior positions (p. 36). The transformational leadership perspective encourages participation and involvement and may help reduce gender discrimination (Broughton \& Miller, 2009, p. 12). 


\section{Prejudices and Discrimination}

Prejudices are preconceived opinions that are not based on reason or experience (Collin, 2006, p. 310). Discrimination is the act of treating someone unjustly based on one's prejudices (Colin, 2006, p. 120). Although prejudices and discrimination toward women in the workforce have diminished, they still exist strongly for women in senior positions (Simpson, 1997, p. 121). These issues, which surface as stereotypes, tokenism, sexism, and the framing of the current state of gender equality against the even greater inequalities of the past are all prevalent for today's executive woman.

Women in high visibility roles are often stereotyped into "role traps," which include the mother, the seductress, the pet and, for those whose management approaches are more directive than collaborative, the iron maiden (Simpson, 1997, p. 122). Due to their lack of female colleagues in management, women are also isolated and are often subconsciously viewed by others in the company as symbolic gestures of the company's goodwill efforts to promote equality. The advancement of a limited number of women into upper echelons of power has created a dynamic labeled "tokenism." This is the interpretation that these few women in positions of power demonstrate equality of opportunity, when in reality, this is far from the truth (Schmitt, Spoor, Danaher, \& Branscombe, 2009, p. 50).

This inaccurate perception of gender equality limits opportunities for women as a group because it creates false optimism and eliminates the perceived need to make things better. "Women who perceive that their opportunities for advancement are hindered by pervasive gender discrimination express stronger gender group identification than do women who perceive gender discrimination as an isolated occurrence" (p. 50). Women will support each other more intentionally when inequality is observed honestly and critically. Token women also find themselves isolated and experience more performancerelated stress. Research also demonstrates that "compared with women who are more equally represented, token women are more likely to experience gender discrimination, receive lower evaluations from male subordinates, and generally experience less career success" (pp. 52-53). A common coping mechanism is the "Queen Bee Syndrome" through which women who have achieved success are not willing to share information or encourage other women to advance. The purpose of this strategy is to maintain a woman's place with the men at her level by aligning herself to the men's perceptions and interests (Hamel, 2009, p. 247).

ECJ Volume 3, No. 2, 2013: $\mathrm{e}^{3}=$ earth education economics 
An insightful blog post about women's leadership issues, Women at the Top, reflects on the issues that token women must face when they are isolated among the higher ranks in a corporation. The Queen Bee Syndrome places a woman in the strained position of wanting to integrate herself with her network of associates but feeling pressured to do so by separating herself from her female colleagues at lower ranks. When there are more women in the higher echelons of an organization, a woman no longer has to choose between being a woman and being a successful executive (Knight, 2011, p. 9).

Closely related to tokenism is the occasional message by media that gender inequality is no longer a problem. By comparing current successful women to the homemakers of the past, news articles sometimes tout examples of successful women as evidence that the glass ceiling is shattered. Although a few women have found their way into positions of power, substantial inequalities still exist in the representation of women generally in senior positions. In some ways, discrimination has become increasingly subtle and hard to detect, creating a more complex environment through which women need to navigate (Schmitt, Spoor, Danaher, \& Branscombe, 2009, p. 55). When media and cultural references focus on women's advances, they create a false perception that current conditions are optimal (p. 56). Discussions of the occasional token female boss and a few women in top positions give the illusion of equality. This is because when companies offer a few women limited, token opportunities, people within the companies perceive that the limited opportunities are as good as equal opportunities (Schmitt, Spoor, Danaher, \& Branscombe, 2009, p. 64). Research participants in different studies valued tokenistic hiring policies as much as equal policies (pp. 61-62). This relaxed concern about the gender equality reduces the perception that improvement is still needed (p. 64).

Finally, all cultures make social distinctions between men and women and place importance of identity in social hierarchy (Harris, 1991, p. 67). This can cover a range of perspectives from hostile differentiation (women are inferior and incompetent) to benevolent differentiation (women are nurturing and possess moral purity) (Eagly \& Mladinic, 1994, p. 17). Men with hostile attitudes towards women target status-seeking women, and when women are in senior positions, they stand out as having threatened male territory. This, together with the fact that senior women are surrounded mostly by male colleagues, places women at further risk of discrimination (Broughton \& Miller, 2009, p. 13). 
Sexism has become more elusive than in the past however (Barreto, Ellemers, Cihangier, \& Stroebe, 2009, p. 102). Even when individuals personally agree with and adopt equal and fair practice, they can still harbour subconscious sexism. "The result is that prejudice is often expressed outside a person's awareness, even when people are subjectively convinced that they do not endorse prejudicial beliefs or are trying hard not to express them" (p. 102).

In Silicon Valley, Ellen Pao, a business partner at Kleiner Perkins, is suing for gender discrimination, retaliation, and sexual harassment. As of June 2012, she had chosen to remain at the company and hold it accountable for not addressing the complaints she filed. Interestingly, the company advertises itself as more gender-diverse than other technical companies. A spokeswoman for the company, Christina Lee, stated, "The number of women partners at the firm is one of the highest within the venture capital arena and the firm has actively supported women in all respects" (Gage, 2012, para. 6). It has 12 women employees on the investment team of 50. This optimistic boasting seems to correlate with the idea that token situations are considered as valid and valuable as equal opportunity situations.

\section{Women's Responses to Barriers}

Women can perpetuate the barriers to their advancement by choosing to respond to difficulty in unhelpful ways. If a woman sees or experiences a barrier, she may respond by internalizing it inappropriately, by rationalizing it through sensemaking, or by avoiding the career altogether. Conversely, the perception that women do not advance because they shrink from opportunity, a choice termed the "ambition gap," is a myth (Lang, 2012, para 2).

When women experience discrimination in the workplace, particularly ongoing subtle forms of discrimination, they tend to internalize the incidents and take responsibility for what went wrong. This is because women in senior positions tend to hold to high standards of meritocracy, the belief that circumstances are largely a result of one's own actions (Barreto, Ellemers, Cihangier, \& Stroebe, 2009, p. 110). The subtle discrimination that is more prevalent today lowers self-esteem. Women in these situations observe implied or vague barriers such as being ignored, overlooked, or resisted. When this happens, they try to figure out what went wrong and take personal responsibility for the incident. This approach does not address the underlying issue if their treatment comes from a colleague or if a superior is discriminating against them in subtle ways, such as not inviting them to a meeting, ignoring them in a conversation, or overlooking a suggestion. If a superior discriminates against them in blatant ways, on the 
other hand, such as making overt statements that women belong in certain roles or restricting educational development to men, the discrimination is easier to resist (Barreto, Ellemers, Cihangier, \& Stroebe, 2009, p. 109). Reduced confidence in their abilities perpetuates women's feelings of inferiority and creates a self-fulfilling effect.

Additionally, studies into women's response to breaks in the corporate contract show interesting facts on how women respond to barriers. Corporate contracts are the unwritten beliefs held by employees about what has been promised to them by their employers, such as increasing pay, job security, training, and promotion (Hamel, 2009, p. 235). Sensemaking involves the rationalizing of incongruent information and events (p. 235). Research has found that women who are treated unfairly, particularly when the anticipated advancement or increased compensation is not actualized, will seek information, make attribution for the barriers, make sense of the incongruence, then act in one of four ways. According to Hamel (2009, p. 250), these actions are to leave quietly, leave while voicing their objections to the discrimination, remain at work and be silent, or remain at work and try to raise awareness to the problem. Although the latter is best to initiate potential change, it is also the most difficult and the least frequent choice. The vast majority of women, 90\%, leave quietly, which perpetuates any unresolved issues within their work environments.

A perspective of this unwillingness to raise awareness about difficult work environments is flagged by Linda Robertson, a lawyer in Vancouver, who writes a blog about legal issues in Canada. In a post from November 15, 2010, she contends that women tend to foster harmony in the workplace and resist asking for raises so that they will not jeopardize their positions. She also discusses a gender bias in which a woman who advocates on her own behalf is seen by her colleagues as pushy and overbearing (Robertson, 2010, para 5).

Finally, another way that women respond to barriers is by avoiding careers in which a higher rate of stereotyping or discrimination will occur. These tend to be male-dominated industries, particularly those that involve skills that are traditionally considered male strengths. Math and science careers are included in this category. Women who experience insecurity about or disparaging reviews of their ability to perform mathematical and scientific tasks choose careers that avoid these tasks (Zhang, Schmader, \& Forbes, 2009, p. 134). Many of these are lucrative careers, so women's absences from them contribute to the compensation gap between the genders. 
A recent argument that women do not advance because they do not try is called the "ambition gap," the perceived propensity for women to choose family before work or to shrink from opportunity. This argument has been discredited by Catalyst's report entitled, "The myth of the ideal worker: Does doing all the right things really get women ahead? (Carter \& Silva, 2011, p. 2). The study involved over 3,000 MBA graduates who stayed on a traditional career path and did not take leave for education, personal or family reasons. It summarized the myth that women did not ask for promotions with this statement, "Women were more likely than men to ask for a variety of skill-building experiences, to proactively seek training opportunities, and to make achievements visible, including asking for feedback and promotions" (p. 11). These actions were not, however, reflected in their advancement. The men and women in the research group who actively pursued advancement found different results. Twice as many men advanced to senior executive levels as women. Further, the researchers found little difference between the women who actively requested advancement and those who were less proactive in their efforts, unlike men who found significant advancement by asking for it (p. 11).

\section{Conclusion}

Although women are generally perceived to have made great strides towards equality in achieving senior positions, the fact remains that women still do not share equal representation in these roles. Executive women are atypical. Complex, pervasive and ongoing barriers limit the progress of millions of women who wish to move into positions of power. The structural, prejudicial, and discriminatory hurdles these women face are often subtle and misunderstood, creating a complex, pervasive, and multi-faceted labyrinth that thwarts any progress they may make. To correct this imbalance, corporations must distinguish the research from the myths and act accordingly.

\footnotetext{
* Author: Dee-Ann Schwanke's experience spans corporate, non-profit, healthcare, government and post-secondary settings. She is a columnist, speaker and community leadership volunteer. Her interest in workplace gender equality stems from contradictions between optimistic reports and statistical evidence regarding executive women. She holds a Bachelor of Commerce with distinction and is completing her Masters in Science in International Management with the University of Liverpool.
} 


\section{References}

Barreto, M., Ellemers, N., Cihangier, S., \& Stroebe, K. (2009). The self-fulfilling effects of contemporary sexism: how it affects women's well-being and behavior. In M. Barreto, M. K. Ryan, \& M. Schmitt (Eds.), The glass ceiling in the 21st century: Understanding barriers to gender equality (pp. 99-123). Washington, DC: American Psychological Association.

Barreto, M., Ryan, M., \& Schmitt, M. (2009). Introduction: Is the glass ceiling still relevant in the 21 st century? In M. Barreto, M. Ryan, \& M. Schmitt (Eds.), The glass ceiling in the 21st century: Understanding barriers to gender equality (pp. 3-19). Washington, DC: Americal Psychological Association.

Broughton, A., \& Miller, L. (2009). Women in senior management: Is the glass ceiling still intact? Is, Guc: The Journal of Industrial Relations \& Human Resources, 11(4), 7-23. doi:10.4026/1303-2860.2009.0122.x

Carter, N. M., \& Silva, C. (2011). The Myth of the ideal worker: Does doing all the right things really get women ahead? Catalyst. Retrieved from http://www.catalyst.org/knowledge/myth-ideal-worker-does-doing-all-right-thingsreally-get-women-ahead

Catalyst. (2007). 2006 Catalyst census of women in Fortune 500 corporte officer and board positions. Retrieved from http:/ /www.catalyst.org/knowledge/2006-catalyst-census-womencorporate-officers-and-top-earners-fortune-500

Cikara, M., \& Fiske, S. (2009). Warmth, competence, and ambivalent sexism: Vertical assault and collateral damage. In M. Barreto, M. Ryan, \& M. Schmitt (Eds.), The glass ceiling in the 21st century: Understanding barriers to gender equality (pp. 73-96). Washington, DC: American Psychological Association.

Collin, P. H. (2006). Dictionary of business. London, UK: A \& C Black.

Eagly, A., \& Mladinic, A. (1994). Are people prejudiced against women? Some answers from research on attiutdes, gender stereotypes, and judgments of competence. European Review of Social Psychology, 5, 1-35.

Eagly, A., \& Sczesny, S. (2009). Stereotypes about women, men and leaders: Have times changed? In M. Barreto, M. Ryan, \& M. Schmitt (Eds.), The glass ceiling in the 21st 
century: Understanding barriers to gender equality (pp. 21-48). Washington, DC: American Psychological Association.

Frenkiel, N. (1984, March). The Up-and-Comers; Bryant Takes Aim At the Settlers-In. Adweek Special Report. Source: Cornell University Catherwood Library (2005, January). Retrieved from http://www.ilr.cornell.edu/library/research/questionofthemonth/jan05.html

Gage, D. (2012, May 22). Kleiner Perkins partner sues for gender discrimination. The Wall Street Journal. Retrieved from http://online.wsj.com/article/SB10001424052702303610504577420442565283020. html?mod=googlenews_wsj

Goleman, D., Boyatzis, R., \& McKee, A. (2002). Primal leadership: Realizing the power of emotional intelligence. Boston, MA: Harvard Business Review Press.

Guerrero, L. (2011). Women and leadership. In W. Rowe, \& L. Guerrero (Eds.), Cases in leadership (pp. 380-412). Thousand Oaks, CA: SAFE Publications.

Hamel, S. (2009). Exit, voice, and sensemaking following psychological contract violations. Journal of Business Communication, 46(2), 234-261.

Harris, M. (1991). Cultural anthropology (3rd ed.). New York, NY: HarperCollins.

Human capital. In Canadian Oxford Dictionary. (2005). Retrieved from https://oxforddictionaries.com/definition/english/human-capital

Knight, R. (2011, June 27). Queen bee in the office: Who gets stung? [Web blog post] Retrieved from http://blogs.ft.com/women-at-the-top/2011/06/27/queen-bee-inthe-office-who-gets-stung/\#axzz1wFoZTOae

Lachance-Grzela, M., \& Bouchard, G. (2010). Why do women do the lion's share of housework? A decade of research. Sex Roles, 63(11/12), 767-780. doi:10.1007/s11199-010-9797-z

Lang, I. H. (2012, January 6). The myth of the ambition gap. Forbes. Retrieved from http://www.forbes.com/sites/forbeswomanfiles/2012/01/06/the-myth-of-theambition-gap/

Robertson, L. (2010, Nov 15). The Gender Compensation Gap. Retrieved from http:/ /www.lindakrobertson.com/?p=47 
Rosener, J. B. (2008). Ways women lead. In T. Donaldson, \& P. H. Werhane (Eds.), Ethical issues in business: A philisophical approach (8th ed., pp. 411-419). Upper Saddle River,NJ: Pearson Prentice Hall.

Rudman, L., \& Heppen, J. (2003). Implicit romantic fantasies and women's interest in personal power: A glass slipper effect? Personality and Social Psychology Bulletin, 29, 1357-1370.

Ryan, M., \& Haslam, S. (2005). The glass cliff: Evidence that women are overrepresented in precarious leadership positions. British Journal of Management, 16, 81-90.

Schmitt, M., Spoor, J., Danaher, K., \& Branscombe, N. (2009). Rose colored glasses: how tokenism and comparisons with the past reduce the visibility of gender inequality. In M. Barreto, M. K. Ryan, \& M. Schmitt (Eds.), The glass ceiling in the 21st century: Understanding barriers to gender equality (pp. 49-71). Washington, DC: American Psychological Association.

Simpson, R. (1997). Have times changed? Career barriers and the token woman manager. British Journal of Management, 8(2), S121-S130.

Stelter, N. Z. (2002). Gender differences in leadership: Current social issues and future organizational implications. Journal of Leadership and Organizational Studies, 8(4), 88-99.

The Canadian Press. (2012, May 29). RCMP commissioner says red tape prevents him from weeding out bad apples quickly. Winnipeg Free Press. Retrieved from http://www.ipolitics.ca/2012/05/28/rcmp-commissioner-says-red-tape-preventshim-from-weeding-out-bad-apples-quickly/

Townsend, B. (1996). Room at the top for women. American Demographics, 18(7), 28-37.

White, E. (2012, Mar 12). Ten sensible tips to achieve work life balance. The Globe and Mail. Retrieved from: http://www.theglobeandmail.com/report-on-business/smallbusiness/sb-tools/the-top-tens/ten-sensible-tips-to-achieve-work-lifebalance/article2364444/

Zhang, S., Schmader, T., \& Forbes, C. (2009). The effects of gender stereotypes on women's career choice: Opening the glass door. In M. Barreto, M. Ryan, \& M. Schmitt (Eds.), The glass ceiling in the 21st century: Understanding barriers to gender equality (pp. 125-150). Washington, DC: American Psychological Association. 